combining 'background' heating by flueless appliances with suitable gas fires. For continuous domestic heating they think the radiating gas fire will take a new form, whether in some measure resembling the coal fires of the past-as it may in the near futureor taking a more revolutionary form. In support of this view they exhibited a gas fire of new design such that any ordinary person walking past would take it for a coal fire of conventional type. Instead of the formal geometrical radiants, it exhibited a face of black mass enclosing glowing cavities surmounted by a play of real flames. There must be many to-day who would find it worth while to pay something extra for the merits of a coal fire without its demerits.

For commercial buildings new designs of overhead radiating panels-both high and low temperature radiators-are now available. In factories, the 'unit heater' which provides a stream of warm air directionally propelled offers many advantages. All these offer considerable advantages over central heating by circulation of hot water, and the paper suggests that great developments may be expected in gas heating.

H. J. Hodsman.

\title{
Structure of Trilobites
}

\author{
By Dr. W. T. Calman, C.B., F.R.S.
}

\begin{abstract}
$\mathrm{T}$ HE trilobites are generally recognized as occupying a key position in relation to the phylogeny of arthropods, and until we have some certainty as to their structure and relationships it is not possible to speculate profitably about the mutual affinities of insects, crustaceans and arachnids. In the course of the last sixty years, a great deal of information regarding their appendages has been obtained, for the most part by American palæontologists; but the results of different investigators have not been easy to reconcile and very divergent conclusions have been drawn regarding the systematic position of the group.
\end{abstract}

Dr. C. D. Walcott, who was the first to obtain definite information about the appendages, worked chiefly on the Ordovician genus Ceraurus, which he studied in thin sections. Dr. C. E. Beecher (whose final memoir was completed after his death by his pupil, P. E. Raymond) studied abundant material of Triarthrus, from the same epoch, as exposed in surface view by splitting the rock. The results of these two workers seemed to reveal an extraordinary difference of structure in the limbs of the two genera. The legs of Ceraurus were provided by Walcott with a pair of corkscrew-shaped gills attached near the base, while those of Triarthrus, according to Beecher, were simply biramous, with the outer branch segmented and fringed on one side with flattened filaments. Taking up the subject again towards the end of his life, Walcott maintained that the spiral 'gills' really existed but now allotted only one of them to each limb and provided it with a row of flattened filaments like those described by Beecher in Triarthmes. In a review of Walcott's paper ${ }^{1}$, I pointed out that the row of filaments, attached to the successive turns of an open helical spiral, would not remain in one plane as they are seen to do in the fossils, unless the spiral were rigid to an improbable degree.

Dr. Leif Størmer, in an important memoir ${ }^{2}$, discusses the whole subject in the light of a re-examination of Walcott's and Beecher's preparations. He has also applied Sollas's method of serial grinding and reconstruction to Ceraurus, and has obtained some very interesting and convincing results. In the first place, the fundamental differences which Walcott supposed to exist between the appendages of Ceraurus and Triarthrus have disappeared. The spiral structures are proved to depend on misinterpretation of the sections. In Ceraurus, as in Triarthrus, the appendages are simply biramous, with an outer branch consisting of a segmented stem fringed on one side with a single row of flattened rod-like or filamentous structures which may, or may not, have served as gills. In view of the poor state of preservation of the appendages in Ceraurus and the obscurity of the traces that they have left in the rock, it is not surprising that many details of their structure must remain uncertain, but Størmer appears to be justified in claiming that all the trilobites so far studied have appendages built on the same plan. Beyond this, however, his far-reaching deductions can only be treated with much reserve.

Impressed with his discovery in Ceraurus (and, very doubtfully, in other genera) of a 'precoxal' segment to which the outer branch of the limb is attached, he designates this outer branch 'preepipodite' and deduces from this that the trilobites have no close relationship with the erustacea but are, on the other hand, intimately associated with the eurypterid-arachnid group. To do this, he has to minimize the importance of those characters in which the trilobites diverge from the Arachnida and approach the Crustacea. To anyone with a sense of morphological values, however, the flagelliform preoral antennules, the five pairs of biramous gnathobase-bearing head appendages following them, and the furcal filaments (of Neolenus) far outweigh the fact that the peduncle of the biramous limbs is unsegmented, as it is, by the way, in not a few Crustacea.

The resemblances between trilobites and primitive arachnids have been often pointed out and are generally admitted, but Størmer does not strengthen his case by taking seriously Schultze's far-fetched comparisons between trilobites and ticks (Ixodidæ). To reason from fortuitous and isolated coincidences of structure is to play into the hands of those who are so ready nowadays to proclaim the bankruptcy of morphology and phylogeny. Anyone who is tempted by such slapdash methods may be recommended to consider the numerous and striking resemblances between trilobites and isopod Crustacea, and then to study carefully the evidence for the derivation of the Isopoda from primitive Mysidacea, which have scarcely anything in common with trilobites except that they are arthropods.

' Geol. Mag., 58, 553 (1922).

2 Studies on Trilobite Morphology. Part I. The Thoracic Appendages and their Phylogenetic Signiflcance".' (Norsk Geol. Tidz8kr., 19, 143-723, 12 pls., text-figs.) 